\title{
POROSIMETRY BY DOUBLE-RANDOM MULTIPLE TREE STRUCTURING IN VIRTUAL CONCRETE
}

\author{
Piet Stroeven $^{1}$, NGHi LB LE ${ }^{\bowtie, 1}$, LAMBertus J Sluys $^{1}$ AND HuAN HE ${ }^{1,2}$ \\ ${ }^{1}$ Faculty of Civil Engineering and Geosciences, Delft University of Technology, PO Box 5048, 2600 GA Delft, \\ the Netherlands; ${ }^{2} \mathrm{GeMMe}$, Minerals Engineering-Materials-Environment, University of Liège, Sart Tilman \\ B52, 4000 Liège, Belgium \\ e-mail: L.B.N.Le@tudelft.nl \\ (Received September 6, 2011; revised November 30, 2011; accepted January 11, 2012)
}

\begin{abstract}
Two different porosimetry methods are presented in two successive papers. Inspiration for the development came from the rapidly-exploring random tree (RRT) approach used in robotics. The novel methods are applied to virtual cementitious materials produced by a modern concurrent algorithm-based discrete element modeling system, HADES. This would render possible realistically simulating all aspects of particulate matter that influence structure-sensitive features of the pore network structure in maturing concrete, namely size, shape and dispersion of aggregate and cement particles. Pore space is a complex tortuous entity. Practical methods conventionally applied for assessment of pore size distribution may fail or present biased information. Among them, mercury intrusion porosimetry and 2D quantitative image analysis are popular. The mathematical morphology operator "opening" can be applied to sections and even provide 3D information on pore size distribution, provided isotropy is guaranteed. Unfortunately, aggregate grain surfaces lead to pore anisotropy. The presented methods allow exploration of pore space in the virtual material, after which pore size distribution is derived from star volume measurements. In addition to size of pores their continuity is of crucial importance for durability estimation. Double-random multiple tree structuring (DRaMuTS), presented herein, and random node structuring (RaNoS) provide such information. The latter method will be introduced in a next issue of Image Anal Stereol.
\end{abstract}

Keywords: DEM, pore connectivity, porosimetry, star volume, virtual concrete.

\section{INTRODUCTION}

Durability risks associated with cementitious materials can be due to transport of harmful substances through the pore system in concrete, water included. Of course, also micro-cracks can be instrumental in this process. But this paper limits itself to porosimetry aspects. Insight into the complex and highly tortuous pore network structure would thus be of practical significance. Various approaches have been applied by researchers for this purpose that yielded quantitative data on aspects of this three-dimensional (3D) network system. A survey of the most practical approaches can be found in Stroeven et al. (2010).

The most frequently used method is doubtlessly mercury intrusion porosimetry (MIP). It offers 3D information, however this could be significantly biased because of the unrealistic schematization of the geometry of the pore channels and the neglect of the so called bottle necks in the pore system (Diamond, 2000). Quantitative image analysis (QIA) is a viable alternative; the approach is basically simple and does not require sophisticated equipment. The obtained information is of two-dimensional (2D) nature, although stereological methods exist for unbiased 3D interpretation. When structural isotropy cannot be guaranteed, however, this may complicate the sampling procedure and will increase labor-intensity of the QIA approach.

A relatively new way of approaching the problem is based on modern computer facilities. Cementitious materials can nowadays be realistically simulated by discrete element modeling (DEM). This is fundamentally different from approaches by forerunners using random generators (RG) for placing particles of cementitious materials inside a container. As a sole example, reference can be given to the development by Wittmann et al. (1985) of so called "numerical concrete" on the basis of Roelfstra's RG-based system (Roelfstra, 1989). A variety of such systems have been and still is employed in concrete technology, a selection of which is referred to in Stroeven et al. (2009). 
DEM far more realistically simulates particulate materials as concrete, both on meso-level where aggregate takes up roughly three-quarter of material volume, and on micro-level where volume density of the cement grains in the fresh material can get as high as $60 \%$ for very low water to cement ratios $(\mathrm{w} / \mathrm{c})$ relevant for (super) high performance concrete (S)HPC. Dispersion and thus spacing of particles in virtual material produced by DEM could be far closer to that in the real material; this is the result of the incorporation of the natural process of particle interference during the "production" of the virtual material. This is of crucial importance for reliable estimation of structuresensitive material properties (Stroeven et al., 2010). The center-to-center spacing of the cement grains in fresh concrete is maintained during maturation $(\mathrm{Hu}$, 2004). Hence, the reliability of the simulated pore depercolation process also depends strongly on the realistic dispersion of the cement grains. Significant differences between process characteristics obtained by (analogue) DEM- and RG-based systems and with the digitized model in Garboczi and Bentz (2001) have been shown in Chen et al. (2006).

When cementitious materials are realistically simulated, the next problem confronting researchers in porosimetry is finding a practical way of detecting the pores, and measuring their size and connectivity; a complicated task. This basically methodological paper will therefore deal with:

1. Production of virtual material

2. Detection of pores

3. Assessment of pore connectivity

4. Measurement of pore size.

\section{PRODUCTION OF VIRTUAL CONCRETE}

Various DEM systems have been developed the past 10 to 15 years. Reference to such systems can be found in Stroeven et al. (2009). Most have been developed for a specific target in concrete technology. The Habanera's discrete element simulator (HADES) system that will be introduced herein is probably an exception to this rule because of its versatility. It can produce any particulate material composed of particles with arbitrary shape from the dilute up to the densest (crystallized) packing state. Some illustrative examples are presented in Fig. 1.

Two methods are in vogue for achieving dense packing states using either static or dynamic algorithms, respectively. HADES is an example of the second category. A dynamic stage organizes particle interference during gradual reduction in the container size. Particle overlap can be prevented by different force systems, which come into action on tessellated surface elements at neighboring sides of approaching particles (Fig. 2). This renders possible packing particles of arbitrary shape. As a consequence, the differences in optimum packing capacity of concrete containing river gravel and crushed rock as aggregate have been investigated this way $(\mathrm{He}, 2010)$. This topic is also of importance for the problem of pore network modeling in compacted concrete (Vogel and Roth, 2001; Stroeven and Guo, 2006) and is therefore of relevance for estimating durability risks.

The somewhat non-spherical nature of cement grains as found by Garboczi and Bullard (2004) can equally be accounted for in the DEM-produced virtual cement (He, 2010; He et al., 2010). The far more complicated hydration algorithms are not yet available, however. For details of the hydration algorithms in the case of spherical cement grains, see Stroeven et al. (2011). Since the impact on topology and geometry of the pore network structure is expected not to be significant, the porosimetry methods that will be introduced have been applied to virtual Portland cement and blended Portland cement pastes consisting of spherical particles.
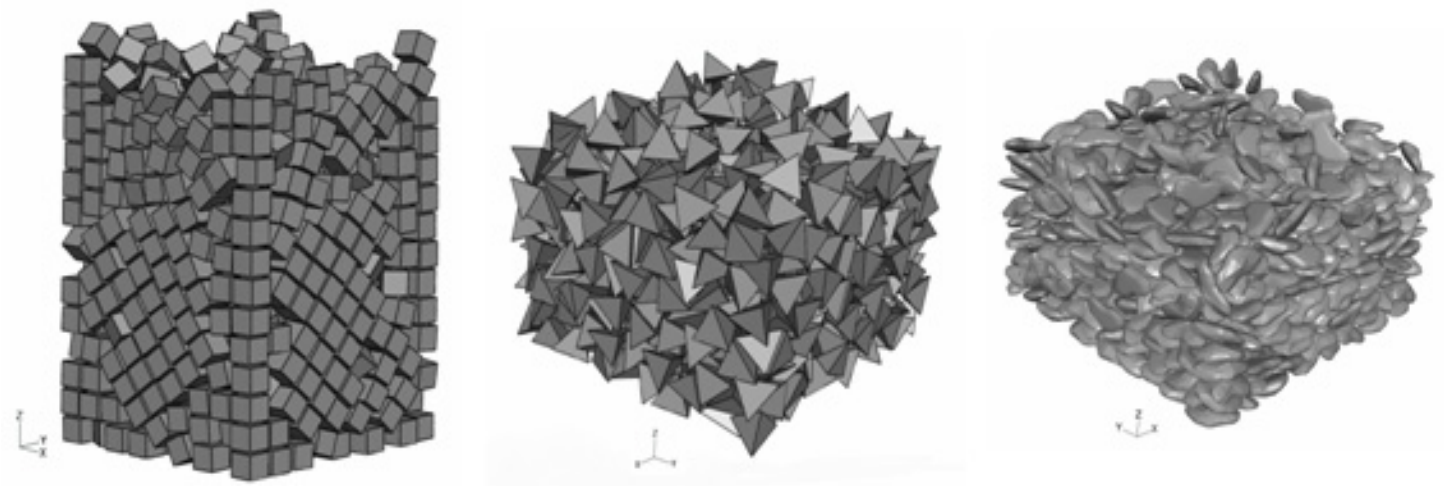

Fig. 1. Examples of loose random packing states of differently shaped particles (He, 2010). 


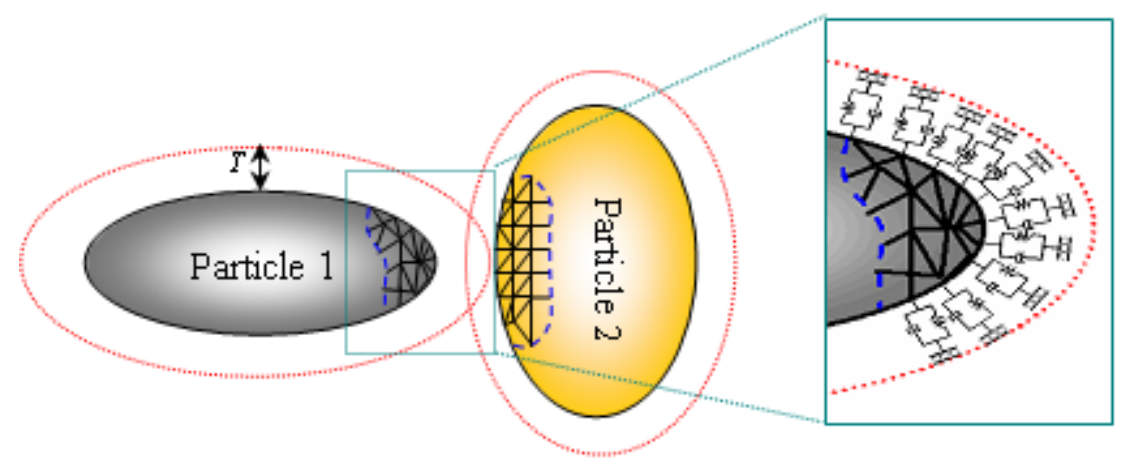

Fig. 2. Mechanisms that come into action upon close encounter of neighboring particles to prevent overlap of such particles. Only tessellated surface elements activated by local overlap of guard zones with thickness T are participating. The intensity of reactive forces depends on local spacing.

Earlier investigations on DEM-made concrete have demonstrated the importance of aggregate grain surfaces for the pore de-percolation process during maturation. Chen et al. (2006) found the fraction of continuous pores (for $w / c=0.3$ ) restricted to an inner layer of the interfacial transition zone (ITZ), adjacent to the aggregate grain surface. The virtual material was produced by the DEM-system SPACE (Software Package for the Assessment of Compositional Evolution), the predecessor of HADES that was based on spherical particles (Stroeven, 1999). Continuity in porosity was assessed by serial sectioning and 3D reconstruction, a popular experimental method when dealing with soft tissues. It was developed by Ye (2003) for virtual concrete, however implemented in the RG-based hydration, morphology and structure formation (HYMOSTRUC3D) system (Breugel, 1991). Total and continuous porosity values were determined as global values by Chen et al. (2006) following this strategy. By assessment of these values in each successive stage of peeling off a layer from the cube specimen (like an onion), the gradient structures of total and continuous porosity were obtained. Steeply declining values were found with zero values inside the ITZ (and in bulk region). For results pertaining to different technological para-meters, see Chen et al. (2004). The major drawback of this approach is its extremely time-consuming character, even in case of virtual concrete. Its unpractical nature in case of physical experiments is obvious.

\section{DOUBLE-RANDOM MULTIPLE TREE STRUCTURING}

Pore characteristics in 3D virtual hydrated paste are investigated by double-random multiple tree structuring (DRaMuTS) approach in which randomized data structures are built incrementally in two stages. In the first stage, the porous medium is rapidly explo- red. In the second stage, pore features such as porosity, gradient structures and connected fraction are evaluated. This allows distinguishing not only between depercolated pores and pores that connected opposite sites of a cube specimen, but also between continuous pore channels and dead-end branches of such channels. Finally, pore size distribution is assessed by star volume measurements on the basis of the randomized point system.

Inspiration for the present approach is derived from the so called 'rapidly-exploring random tree' (RRT) algorithm in robotics developed in LaValle and Kuffner (2001). This efficient path planning algorithm pursues finding a way from point $\mathrm{A}$ to point $\mathrm{B}$, avoiding any collision with dispersed obstacles. Path planning is implemented by generating a 'virtual tree' system that includes sets of nodes ('vertices') and lines ('edges') that connect pairs of nodes (like branches of real trees). This tree grows incrementally and randomly in 3D. Procedure starts by generating a random point that is then moved towards the nearest vertex, thereby defining a maximum incremental distance. Next, a check for collision with an obstacle is executed. No collision leads to addition of a new point and a segment to the tree. At collision, a new random point is generated and the procedure is repeated until the goal is achieved. The expansion of the tree is illustrated in Fig. 3 (top).

The RRT method needed significant upgrading for porosimetry applications. Since a large number of trials may be involved, generation of the complete tree system would be laborious. In the present approach, therefore, instead of boosting the no-collision trials, intersections of the tested segment and obstacles (solid phase in hydrated cement paste) are detected. Next, a point is trimmed between the nearest intersection and the considered vertex and then becomes a new vertex as in Fig. 3 (bottom). This excludes making iterations, 
because there is always one new vertex in the generation process. This speeds up the generation of the whole tree system and constitutes therefore a significant improvement of the RRT algorithm. Moreover, this allows investigating also dead-end branches of continuous pore channels.
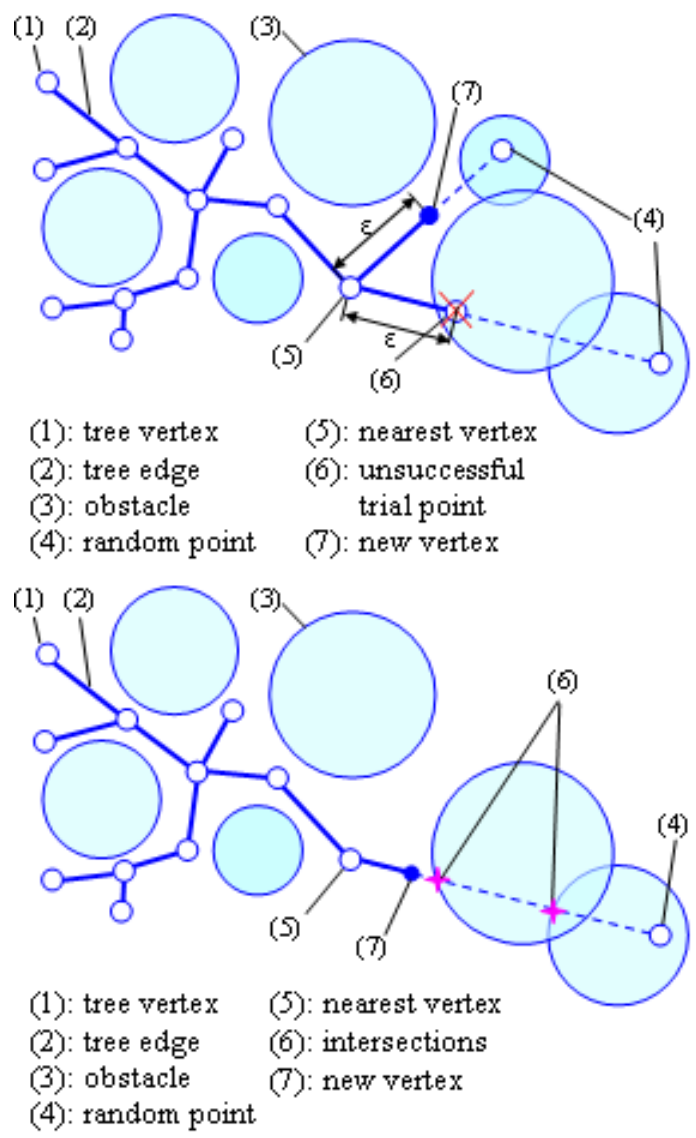

Fig. 3. Expansion of tree system by RRT (top) and by DRaMuTS, respectively (bottom).

Exploration by a single tree system seems not appropriate in porosimetry. Parallel development at the same time leads to the so called 'multiple-tree' network. Herein, tree systems grow incrementally from a set of different points referred to as 'seeds', which are randomly distributed in pore space. Interestingly, sowing can be achieved on one side of the paste model, alternatively, on both opposite sides; sowing can be realized inside the paste model and it can be a combination of the preceding procedures. Additionally, efficiency can be improved by sowing the seeds in the gaps between hydrated neighboring cement grains. Upon completion of the generation process, the connectivity between the tree systems is checked. If so, trees will merge into a single one.

After completion of pore exploration, the second stage of the DRaMuTS approach starts, in which pore features are investigated. To start with, random points are generated in the model cement paste, which is expressed by 'double random' in the name of the approach. The first stage-produced tree vertices in percolated as well as in de-percolated pores allow a fast classification of the random points into three groups, encompassing points inside percolated or depercolated pore phase or in solid phase, respectively. Only the points inside pore space are considered in further investigations. Counting points suffices for the assessment of associated fractions of porosity. A direct connection between opposite paste surfaces is defined as a 'main trunk'. This renders possible separating between main trunks and dead-end branches in the fraction of percolated porosity.

\section{PORE SIZE IN 3D}

In $2 \mathrm{D}$ sections of real or virtual concrete alike, the most direct way of obtaining 3D local volume information on irregularly shaped pores is by way of the mathematical morphology operator "opening" (Serra, 1982). This has been accomplished in $\mathrm{Hu}$ and Stroeven $(2005 ; 2006)$ and Stroeven et al. (2010). The underlying requirement of structural isotropy can be expected violated however inside the ITZ, so the method should be applied to bulk cement only. A next option is making star volume measurements; a method employed in life sciences (Gundersen et al., 1988; Smit et al., 1998).

A 3D pore structure is produced by HADES and explored and visualized by the new porosimetry methods introduced herein and in a next IA\&S publication. Hence, a direct 3D assessment method for pore size would be attractive. Ye (2003) and Ye et al. (2003) had the (by serial sectioning and 3D reconstruction generated) pore network filled up by spheres of successively increasing size, starting from a pre-determined point. This has been indicated leading to biased results $(\mathrm{Hu}, 2004$; $\mathrm{Hu}$ and Stroeven, 2006). Instead, the earlier mentioned technique of star volume measurements can be applied in 3D. The 3D "stars" are positioned at random points inside the pore system. Next, a large number of "pikes" extends from the star center to the nearest pore surface. Their length, $l_{\mathrm{i}}$, is measured, whereupon local pore volume, $V_{\mathrm{i}}$, is obtained from (Gundersen et al., 1988)

$$
V_{\mathrm{i}}=\frac{4}{3} \pi \overline{l_{\mathrm{i}}^{3}},
$$

so that local pore size (i.e., diameter) equals $2 \sqrt[3]{l_{\mathrm{i}}^{3}}$. The volume-based cumulative pore size distribution 
function is mathematically given by

$$
F(s)=\frac{\int_{\Omega_{1}(s)} d V}{\int_{\Omega} d V},
$$

where $\Omega$ is the total pore space and $\Omega_{1}(s)$ is the space of pores whose sizes are smaller than $s$. Since the random points are uniformly distributed in the pore space, the random points can be considered as a discretized system of the pore space. Let pore size $s$ be discretized by a limited number of sizes $s_{k}(k=$ $1,2 \ldots, M)$, then the cumulative function is reflected at $s_{k}$ as

$$
F\left(s_{k}\right)=\frac{\sum_{i=1}^{N} B\left(s_{k}>s_{i}\right)}{N},
$$

where $N$ is the total number of random points, and $B($ ) is a Boolean function that equals 1 if the condition between the brackets is satisfied and is 0 otherwise. Subsequently, the real volume-based pore size distribution function, $\mathrm{p}_{\mathrm{o}} \mathrm{sd}$, is obtained through derivation of the cumulative functions as

$$
f\left(s_{k}\right)=\frac{F\left(s_{k+1}\right)-F\left(s_{k-1}\right)}{s_{k+1}-s_{k-1}}
$$

\section{DRaMuTS EXAMPLE}

Details of an example of the DRaMuTS approach for the exploration of pore space in hydrated virtual plain Portland cement paste and in gap-graded blended Portland cement paste are presented in Table 1 (Stroeven et al., forthcoming 2012). Note that $w / b$ is the water to binder ratio (the binder encompasses the Portland cement and the mineral admixture), and $\mathrm{P}$ and $\mathrm{R}$ stand for periodic and rigid boundary conditions of the simulated pocket of material, respectively.
To obtain matured virtual cement paste, initially the cement particles are randomly generated in a large container. Next, the packing process is realized by gradually reducing the container size while particles move and collide among each other and with the rigid container surfaces until the desired packing density is obtained. Overlap is prevented by the mechanisms indicated in Fig. 2. Six periodic boundaries are assigned to the container for simulating bulk material (PC1 and BPC1 samples). For simulating the ITZ zone (PC2 and BPC2 samples), four periodic and two opposite rigid boundaries are used. Gradient structures are formed adjacent to the rigid surfaces due to the wall effect (Stroeven and $\mathrm{Hu}, 2007)$. Also after hydration such gradient structures are found. The relevant cement hydration simulation (CemHydSim) program, is described in detail in Stroeven et al. (2011). This boundary zone denotes the interfacial transition zone (ITZ) in concrete technology. As an example, porosity in the ITZ is found exceeding that in bulk material in agreement with experimental data. In this research, the rigid surfaces are due to the coarse aggregate like river gravel or crushed rock. The order of magnitude size differences between aggregate and cement grains allows simulating the aggregate surface in the form of a flat container side. For details, see Stroeven and Stroeven (2001).

As mentioned above, the capillary pores are distinguished into de-percolated pores and pores that connected opposite sites of a cube specimen. The connected fraction in Table 2 is defined as the volume ratio of percolated pores to that of all capillary pores. Practically, this means that from any point in the percolated pores the two external periodic surfaces of the specimen can be reached. For estimation of transport-based durability properties, the very fine pores detected at the high sensitivity level applied might not be contributing significantly to transport through the specimen. When they are removed for this

\begin{tabular}{|c|c|c|c|c|c|c|c|c|}
\hline & \multirow{2}{*}{$\begin{array}{l}\text { Boundary } \\
\text { conditions }\end{array}$} & \multicolumn{2}{|c|}{$\begin{array}{l}\text { Diameter range }(\mu \mathrm{m}) \text { and } \\
\text { volume percentage }(\%)\end{array}$} & \multicolumn{2}{|c|}{$\begin{array}{l}\text { Specific surface area } \\
\left(\mathrm{cm}^{2} / \mathrm{g}\right)\end{array}$} & \multirow{2}{*}{$\begin{array}{c}\text { Size of } \\
\text { pocket }(\mu \mathrm{m})\end{array}$} & \multirow{2}{*}{$\begin{array}{l}\text { Initial } \\
w / b \text { ratio }\end{array}$} & \multirow{2}{*}{$\begin{array}{c}\text { Number of } \\
\text { particles }\end{array}$} \\
\hline & & $\mathrm{PC}$ & blended & $\mathrm{PC}$ & blended & & & \\
\hline PC1 & $6 \mathrm{P}$ & \multirow{2}{*}{$\begin{array}{c}3 \sim 30 \\
(100 \%)\end{array}$} & & \multirow{2}{*}{1450} & \multirow{2}{*}{ - } & \multirow{2}{*}{100} & \multirow{2}{*}{0.299} & \multirow{2}{*}{1090} \\
\hline $\mathrm{PC} 2$ & $4 P+2 R$ & & & & & & & \\
\hline BPC1 & $6 \mathrm{P}$ & \multirow{2}{*}{$\begin{array}{c}3 \sim 30 \\
(85.82 \%)\end{array}$} & \multirow{2}{*}{$\begin{array}{c}1.5 \sim 2 \\
(14.18 \%)\end{array}$} & \multirow{2}{*}{1428} & \multirow{2}{*}{9994} & \multirow{2}{*}{100} & \multirow{2}{*}{0.299} & \multirow{2}{*}{18150} \\
\hline BPC2 & $4 P+2 R$ & & & & & & & \\
\hline
\end{tabular}
practical purpose the connected fraction will decline.

Table 1. Characteristics of simulated cement samples. 
Table 2. Experimental details.

\begin{tabular}{cccc}
\hline & $\begin{array}{c}\text { Ultimate } \\
\text { DOH }\end{array}$ & $\begin{array}{c}\text { Porosity } \\
p(\%)\end{array}$ & $\begin{array}{c}\text { Connected } \\
\text { fraction } \\
\text { of } p(\%)\end{array}$ \\
\hline PC1 & 0.715 & 5.50 & 99.78 \\
PC2 & 0.715 & 5.44 & 99.66 \\
BPC1 & 0.715 & 5.26 & 99.80 \\
BPC2 & 0.715 & 5.20 & 99.78 \\
\hline
\end{tabular}

The random tree structures in Fig. 4 are both obtained at the level of 10,000 tree edges (shown later to correspond to an intermediate sensitivity). Different trees have different colors. Obviously, gap-graded blending with a pozzolanic admixture (rice husk ash served as reference) leads to fractionalization in the pore network. However, at increasing sensitivity, most of the pore system becomes continuous by pore connections of decreasing diameters, as reflected by Table 2. At this 'optimum' sensitivity, total porosity is found declining somewhat in the blending case.
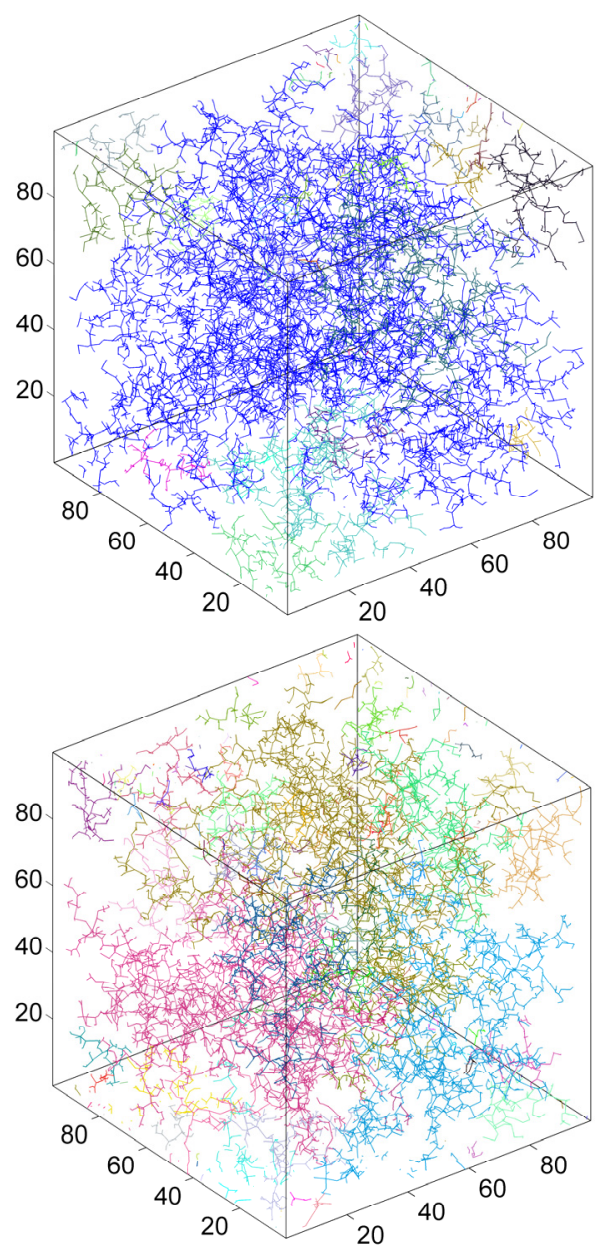

Fig. 4. Exploration by DRaMuTS in virtual hydrated Portland cement paste (sample PC2) at the top and gap-graded blended Portland cement paste (sample BPC2), at the bottom, both with 10,000 tree edges.
The probability of detecting such tiny connections ('ink-bottles") between initially dead-end pores increases indeed with the number of generated points or edges. However, these very small pores may have limited impact on transport capabilities. So, a lower sensitivity level can be selected because of relevance for durability issues. As a result, pore trees consisting of continuous pores and dead-end pores branching off such main trunks would be a realistic concept that could underlie durability estimates.

Hence, getting to the outside of the hardened pocket from a random point in a pore is more difficult or less straight forward in the blended case. As a result, transport-based durability capacity of concrete can be expected favored by gap-graded blending.
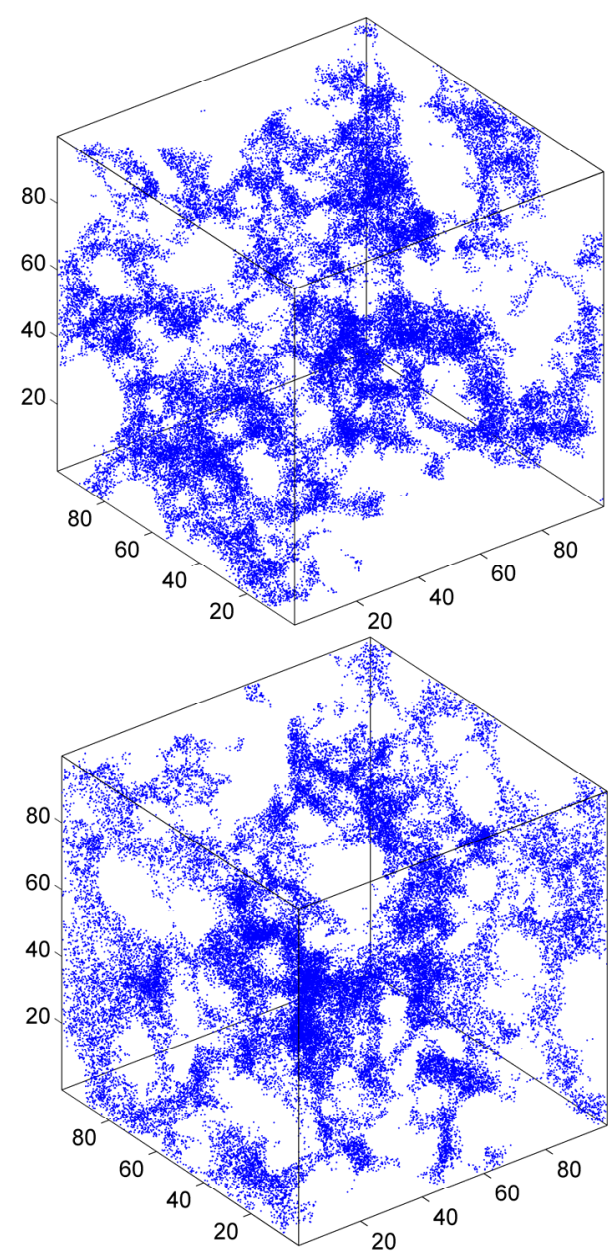

Fig. 5. Distribution of random points generated in the second stage of the DRaMuTS approach and located in pore space of sample PC2, at the top, and of sample $B P C 2$, at the bottom.

Of the points randomly dispersed in the second stage of the DRaMuTS approach, those outside pore space are removed. The result is displayed in Fig. 5. Fig. 6 shows the gradient structures of porosity in the four different samples. The zone of enhanced porosity 
inside the ITZ around aggregate grains is reduced by the gap-graded blending. Hence, the effect on global transport will be reduced.
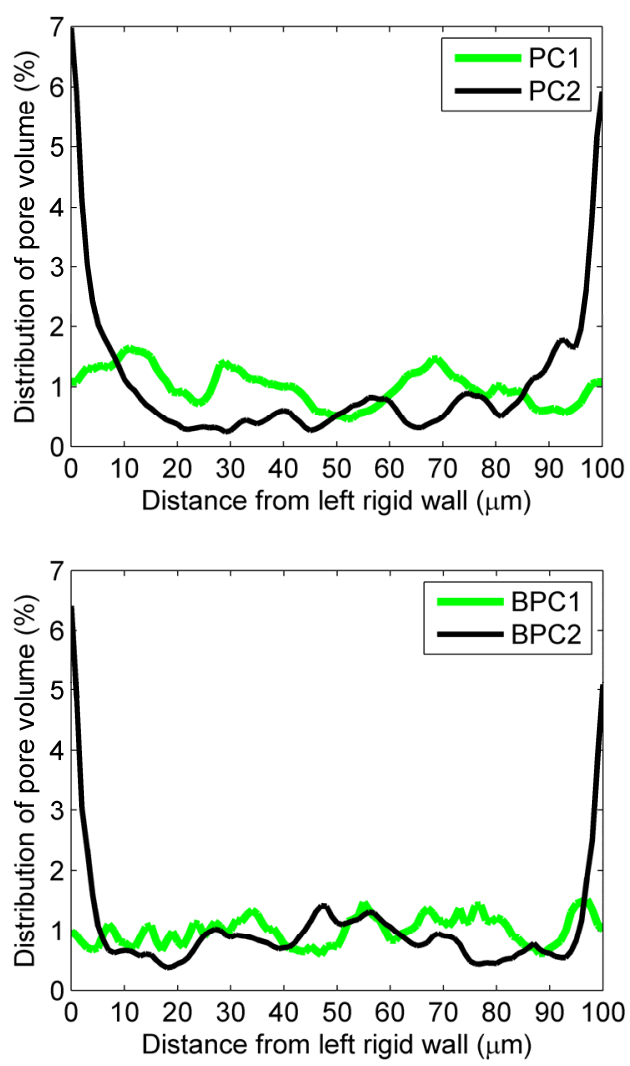

Fig. 6. Gradient structures in connected pore volume at two different boundary conditions and for PC, at the top, and gap-graded blended PC, at the bottom.

Finally, Fig. 7 presents volume-based pore size distribution functions of plain and blended cases both investigated at 'highest' sensitivity (i.e. 100,000 tree edges in first stage and 1000,000 random points in second stage are used in both cases). Data are obtained by star volume measurements. The differences in pore size distribution will increase at equal sensitivity level. In addition to fractionalization and increased pore tortuosity (Fig. 4), blending leads to refinement in the pore structure; another factor that will positively affect concrete durability due to hampered transport through the material.

The sensitivity analysis presented in Fig. 8 offers insight into the number of tree edges (or number of generated points) required for obtaining a stable value of the 'fraction of connected edges'. The latter is defined as the total length of the tree edges connected to both opposite surfaces of the sample pocket versus total length of the generated tree edges. At very large numbers, most of the pores are connected to the outside surfaces, as also indicated in Table 2.

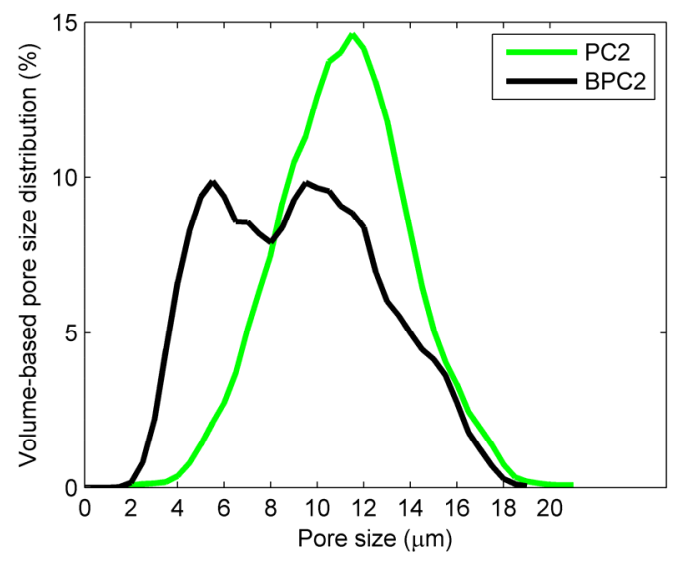

Fig. 7. Pore size distribution functions for plain and blended Portland cement.

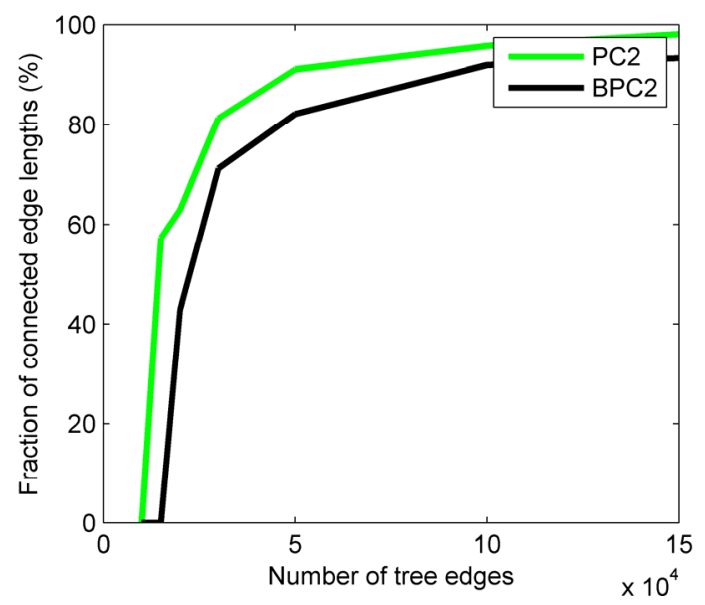

Fig. 8. Sensitivity analysis of the fraction of connected edge lengths.

\section{DISCUSSION}

Present day computer technology renders possible using a modern DEM system for simulating concrete. It has been proven in the open literature (see, e.g., Stroeven et al., 2009)) that conventionally applied random sequential addition (RSA) systems, which are based on randomized particle addition, do not present reliable information when structure-sensitive material properties are at issue. Also fully randomized approaches to digitized material models such as proposed by national institute of standards and technology (NIST) researchers (Garboczi and Bentz, 2001) lead to biases as also shown in the aforementioned paper. Reality is between the too evenly distributed particle dispersion in RSA systems and the chaotic dispersion state in the latter approach. The development of the depercolating pore system during hydration is such an example. The HADES system on which this study is based offers a modern concurrent algorithm-based dynamic approach, 
simulating also the production conditions of the material whereby particle interference is a major mechanism.

Experiments on gap-graded rice husk ash-blended Portland cement concrete confirmed the improved efficiency of gap-graded blending (Bui et al., 2005). Earlier simulation results (obtained by the concurrent algorithm-based dynamic SPACE system) revealed this to be due to the improved packing density in the ITZ. The present paper adds to these results the positive effects on pore refinement that will have a favorable impact on transport-based durability performance of the material.

This paper deals with an ongoing study in the field of porosimetry on virtual concrete. A novel method is presented. This may open new horizons for durability predictions. Popular methods for estimation of durability properties are based on quantitative image analysis results or involve practical approaches discussed elsewhere (Stroeven et al., 2009), the evaluation of which depends on non-realistic assumptions for pore geometry. Hence, the new topological and geometric information on the spatial pore network structure that comes available would probably also ask for novel ways to approach durability issues.

The ITZ is shown to play an important role in the transport process that may eventually lead to durability problems. This dominant position of the ITZ is widely accepted. To verify this by direct measurement would be very complicated. The present authors are unaware of such tests. Contrary, the presented computer simulation approach would offer at least an easier and far more economical solution. Such a study is foreseen for the near future.

\section{CONCLUSIONS}

A novel approach to porosimetry in virtual concrete is presented that combines reliability and economy. This method relies on realistic analogue simulations of fresh cementitious materials by a dynamic concurrent algorithm-based DEM system, HADES. During simulated maturation, the process of pore de-percolation can be numerically assessed. To do so, the evolving pore network structure is analyzed by DRaMuTS of which development is inspired by experiences in robotics. The method renders possible separating between continuous pores, dead-end pores branching off such trunks, and isolated pores.

Tree-like pore network structures are obtained of which volume density is highest adjacent to the aggregate grain surface inside the ITZ. As to this aspect, they confirm results obtained by the far more laborious approach of serial sectioning and $3 \mathrm{D}$ reconstruction.

However, fundamentally different is the finite value observed for connected pore volume in bulk. This is due to the dead-end pores branching off the trunks inside ITZs that will lead to connections between pores of neighboring ITZs. Aggregate grains have been demonstrated coming close enough to cause ITZ percolation. In such percolated ITZ zones of neighboring aggregate grains is the probability highest for pore trees to get mutually connected through their dead-end branches. The result is that the dense random packing of the aggregate leads to connected pathways (trunks) over the full extension of concrete specimens or elements.

Gap-graded blending of the PC leads to reduced transport capacity of the hardened material. This is due to increased tortuosity and refinement of the continuous fraction of the pore system. This adds to positive experimental findings on the mechanics of gap-graded rice husk ash blended Portland cement concrete that were supported by particle packing simulations with the concurrent algorithm-based SPACE system (Bui et al., 2005). Also on the basis of gapgrading, strength is even found positively influenced when an inert mineral admixture (carbon black) was applied (Goldman and Bentur, 1993). This is the result of high packing density favoring the development of significant physical contributions (of Vander Waals nature) to material strength. Investigations with DraMuTS are underway aiming to reveal also positive effects on durability resistance in this case.

\section{REFERENCES}

Breugel KV (1991). Simulation of cement hydration and formation of structure in hardening cement based materials. PhD Thesis, Delft University of Technology. Delft.

Bui DD, Hu J, Stroeven P (2005). Particle size effect on the strength of rice husk ash blended gap-graded Portland cement concrete. Cem Concr Compos 27: 357-66.

Chen HS, Ye G, Stroeven P (2004). Computer simulation of structure of hydrated cement paste enclosed by inter-facial transition zone in concrete. In: Setzer MJ, Palecki S, eds. Proceedings of International Conference on Durability of High Performance Concrete and Final Workshop of CONLIFE, 2004 September 23-24; Essen, Germany. Freiburg: Aedificatio Publishers, 133-44.

Chen HS, Stroeven P, Ye G, Stroeven M (2006). Influence of boundary conditions on pore percolation in model cement paste. Key Eng Mater 302-303: 486-92.

Diamond S (2000). Mercury porosimetry: an inappropriate method for the measurement of pore size distributions 
in cement-based materials. Cem Concr Res 30:151725 .

Garboczi EJ, Bentz DP (2001). The effect of statistical fluctuation, finite size error, and digital resolution on the phase percolation and transport properties of the NIST cement hydration model. Cem Concr Res 31: 1501-14.

Garboczi EJ, Bullard JW (2004). Shape analysis of a reference cement. Cem Concr Res 34: 1933-7.

Goldman A, Bentur A (1993). The influence of microfillers on enhancement of concrete strength. Cem Concr Res 23:962-72.

Gundersen HJG, Bagger P, Bendtsen TF, Evans SM, Korbo L, Marcussen N, et al. (1988). The new stereological tools: Disector, fractionator, nucleator and point sampled intercepts and their use in pathological research and diagnosis. APMIS 96(7-12):857-81.

He H (2010). Computational Modelling of Particle Packing in Concrete. PhD Thesis, Delft University of Technology. Delft.

He H, Guo Z, Stroeven P, Stroeven M, Sluys LJ (2010). Strategy on simulation of arbitrary-shaped cement grains in concrete. Image Anal Stereol 29:79-84.

Hu J (2004). Porosity in concrete - morphological study of model concrete. PhD Thesis, Delft University of Technology. Delft.

Hu J, Stroeven P (2005). Depercolation threshold of porosity in model cement: approach by morphological evolution during hydration. Cem Concr Compos 27:19-25.

$\mathrm{Hu}$ J, Stroeven P (2006). Proper characterization of pore size distribution in cementitious materials. Key Eng Mater 302-303:479-85.

LaValle SM, Kuffner JJ (2001). Rapidly-exploring random trees: Progress and prospects. In: Donald BR, Lynch KM, Rus D, eds. Algorithmic and Computational Robotics: New Directions. Wellesley, MA: A K Peters, 293308.

Roelfstra PE (1989). A numerical approach to investigate the properties of numerical concrete. PhD Thesis, Ecole Polytechnique Fédérale de Lausanne. Lausanne.

Serra J (1982). Image analysis and mathematical morphology. London: Academic Press.

Smit TH, Schneider E, Odgaard A (1998). Star length distribution: a volume-based concept for the characterization of structural anisotropy. J Mircosc 191:249-57.
Stroeven M (1999). Discrete numerical modelling of Composite Materials - application to cementitious materials. PhD Thesis, Delft University of Technology. Delft.

Stroeven P, Stroeven M (2001). Reconstructions by SPACE of the Interfacial Transition Zone. Cem Concr Compos 23:189-200.

Stroeven P, Guo Z (2006). Modern routes to explore concrete's complex pore space. Image Anal Stereol 25: 75-86.

Stroeven P, Hu J (2007). Gradient structures in cementitious materials. Cem Concr Compos 29:313-23.

Stroeven P, Hu J, Stroeven M (2009). On the usefulness of discrete element computer modeling of particle packing for material characterization in concrete technology. Comput Concr 6:133-53.

Stroeven P, Hu J, Koleva DA (2010). Concrete porosimetry: Aspects of feasibility, reliability and economy. Cem Concr Compos 32:291-9.

Stroeven P, Le NLB, Stroeven M, Sluys LJ (2011). Discrete element modeling approach to porosimetry for durability risk estimation of concrete. In: Oñate E, Owen DRJ, eds. Proceedings of PARTICLES 2011, II International Conference Particle-based Methods, Fun-damentals and Applications (on CD), 2011 October 26-28; Barcelona, Spain.

Stroeven P, Le NLB, He H (forthcoming 2012). Methodological approaches to $3 \mathrm{D}$ pore structure exploration in cementitious materials. In: Proceedings of the 13th International Conference on Non-conventional Materials and Technologies, 2011 September 22-24; Changsha, China.

Vogel HJ, Roth K (2001). Quantitative morphology and network representation of soil pore structure. Adv Water Resour 24:233-42.

Wittmann FH, Roelfstra PE, Sadouki H (1985). Simulation and analysis of composite structures. Mater Sci Eng 68:239-48.

Ye G (2003). Experimental study and numerical simulation of the development of the micro-structure and permeability of cementitious materials. PhD Thesis, Delft University of Technology. Delft.

Ye G, Breugel Kv, Fraaij ALA (2003). Three-dimensional microstructure analysis of numerically simulated cementitious materials. Cem Concr Compos 33:215-22. 